\title{
Facial Fractures in Preschool- and School-aged Children
}

\author{
Marwa A Attyia ${ }^{1}$, Salwan Y Bede ${ }^{2}$, Mudher MB Alsunbuli ${ }^{3}$, Imad S Noorali ${ }^{4}$
}

\begin{abstract}
Aim: The purpose of this study was to analyze the patterns of facial fractures in children and to compare them between preschool- and schoolaged children.

Materials and methods: This retrospective observational study included 57 children with facial fractures. The variables analyzed were the age of the patients - divided into a preschool-aged group ( $0-5$ years) and a school-aged group (6-12 years) - gender, cause of trauma, the facial bones involved, the pattern of fracture, the modality of treatment used, the time between injury and treatment, and the postoperative complications. Results: The incidence of facial fractures in children $\leq 12$ years was $30.2 \%$. The patients consisted of $40(70.2 \%)$ males and $17(29.8 \%)$ females, and most patients belonged to the school-aged group $(n=35,61.4 \%)$. The most common cause of injury was falls. Mandibular fractures were the most common (54.2\%), mostly involving the condylar region. Forty patients (70.2\%) were treated surgically and 17 patients (29.8\%) were managed conservatively. The variables that were significantly different between the two groups included the cause of injury, the site of injury, and the type of treatment.

Conclusion: Facial fractures occur most frequently in school-aged children with male predominance, falls are the most common cause of facial fractures in children, the incidence of mandibular fractures is high and the condyle is the most affected site, the surgical treatment is indicated in most of the older age groups, and no major complications were encountered.

Clinical significance: Facial fractures in children require special considerations in their management due to many characteristic features of the facial skeleton of the growing child and the possibility of growth disturbances that may result from these injuries, the incidence of facial fractures in children increases with the beginning of school and their treatment in school-aged children tends to be surgical rather than conservative.

Keywords: Facial fractures, Maxillofacial fractures, Maxillofacial injuries.

World Journal of Dentistry (2019): 10.5005/jp-journals-10015-1640
\end{abstract}

\section{INTRODUCTION}

Maxillofacial fractures occur in less than $15 \%$ of patients younger than 16 years of age, and less than $1 \%$ of all facial fractures occur in children younger than 5 years of age; ${ }^{1}$ the incidence rises when children begin schools and during puberty and adolescence with increased unsupervised physical activity and sports. ${ }^{2}$

According to the World Health Organization definition, children are considered in the age range of $0-18$ years, ${ }^{3}$ but when studying maxillofacial trauma in children, Thorén et al. ${ }^{4}$ advocated drawing a limit at 10 years, since according to their results, etiological factors and fracture patterns in patients older than 10 years resembled those found in adults.

Certain facial features characterize children: higher cranialfacial skeletal size ratio, small size of the face, elastic bone, thick soft tissues, and lack of pneumatization of the paranasal sinuses; it is because of these features that treatment of facial fractures needs to be undertaken with special considerations. ${ }^{5,6}$

Causes of facial injury can be: road traffic accidents (RTA); falls (both from a height and at ground level); sport injuries; interpersonal violence, among others. ${ }^{1}$ Various studies have published data on the etiologies of pediatric injuries that vary from one country to another, probably due to the differences in social, cultural, and environmental factors. ${ }^{7}$

Male preponderance is constantly reported and this is attributed to more physical activities among boys, but this gender difference is less significant in younger age groups. The percentage of the various etiologies reported depends on the age groups investigated and on the types of fractures included; while young children usually sustain injuries from low-velocity forces such as
1,3,4 Oral and Maxillofacial Surgery Unit, Al-Yarmouk Teaching Hospital, Baghdad, Iraq

${ }^{2}$ Department of Oral and Maxillofacial Surgery, College of Dentistry, University of Baghdad Bab-Almoadham, Baghdad, Iraq

Corresponding Author: Salwan Y Bede, Department of Oral and Maxillofacial Surgery, College of Dentistry, University of Baghdad BabAlmoadham, Baghdad, Iraq, Phone: +964 7906210006, e-mail: salwan. bede@gmail.com

How to cite this article: Attyia MA, Bede SY, et al. Facial Fractures in Preschool- and School-aged Children. World J Dent 2019;10(3): 197-201.

Source of support: Nil

Conflict of interest: None

falls, older children are more likely to be exposed to high-velocity forces (e.g., in RTA, sports-related trauma). ${ }^{2}$

In principle, management of facial fractures in pediatric population is similar to that of the adult patients, which consists of reduction, fixation, and immobilization, but in children even when surgical treatment is advocated, one needs to be as conservative as possible keeping the manipulation as minimal and as less invasive as possible, and despite the fact that open reduction and internal fixation is, nowadays, considered to be the standard care for maxillofacial fractures, its use in children is controversial. ${ }^{5}$ There appears to be few studies that are concerned with pediatric facial fractures in Iraq; therefore, the aim of this study was to evaluate and analyze maxillofacial fractures in children in terms of incidence, patterns of injury, causes, and treatment modalities

() The Author(s). 2019 Open Access This article is distributed under the terms of the Creative Commons Attribution 4.0 International License (https://creativecommons. org/licenses/by-nc/4.0/), which permits unrestricted use, distribution, and non-commercial reproduction in any medium, provided you give appropriate credit to the original author(s) and the source, provide a link to the Creative Commons license, and indicate if changes were made. The Creative Commons Public Domain Dedication waiver (http://creativecommons.org/publicdomain/zero/1.0/) applies to the data made available in this article, unless otherwise stated. 
and to compare these variables between preschool-aged and school-aged children.

\section{Materials and Methods}

This retrospective observational study included children $\leq 12$ years of age who have sustained fractures involving the maxillofacial region and were treated at the Oral and Maxillofacial Surgery Unit of Al-Yarmouk Teaching Hospital during the period from January 2017 to September 2018. The patients were divided into two age groups: the first age group included preschool-aged children with an age range of $0-5$ years; the second group included school-aged children with an age range of 6-12 years. Patients who received definitive treatment elsewhere, were lost to follow-up, or diagnosed with pure soft tissue or dental injuries were excluded from this study.

Preliminary trauma evaluation was carried out at the emergency department of the same hospital before the patients were transferred for definitive management.

Diagnosis of facial fractures was based on history, clinical examination, imaging, and other investigations. A thorough history was obtained from all the patients and/or their escorts (legal guardians and parents). Information about the cause, mechanism of injury, and time from injury to presentation were recorded. This was followed by complete extra- and intraoral examination. Radiographic imaging was requested for further confirmation and characterization of the fracture type, location, and pattern. Multiple modalities were used in varying situations. In general, two views perpendicular to each other were obtained to visualize the fractures in at least two planes. Computerized tomography scan (CT scan) was also used in some cases.

Treatment of pediatric maxillofacial fractures was either conservative or surgical. Conservative treatment consisted of close observation, soft diet, analgesics, and activity precautions with regular follow-up. This approach was indicated for most nondisplaced mandibular fractures with reproducible nondisturbed occlusion. Intracapsular condylar fractures and subcondylar fractures without significant malocclusion were also managed conservatively with early jaw mobilization.

The surgical treatment, on the contrary, consisted of closed reduction and immobilization using arch bar and intermaxillary fixation (IMF), circummandibular wiring, and pyriform aperture internal suspension wiring (Fig. 1). This type of treatment was indicated in mandibular fractures with malocclusion, dentoalveolar fractures, and nasal fractures which were treated with manipulations and

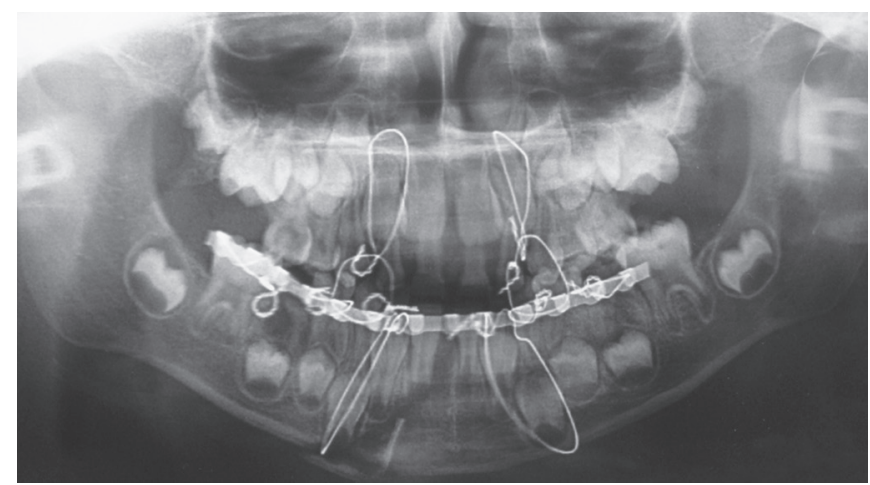

Fig. 1: A panoramic view of a 6-year-old patient with right parasymphyseal fracture of the mandible treated by IMF with lower arch bar, circummandibular wiring, and pyriform aperture internal wire suspension external splinting. Open reduction and internal fixation (ORIF) was reserved for unfavorably displaced mandibular fractures, which were managed with titanium miniplates and monocortical screw fixation (Fig. 2).

Postoperatively, antibiotics were prescribed for at least 7 days. Patients and their parents were instructed to maintain adequate oral feeding in the form of liquid or soft diet. The follow-up period lasted for at least 2 months postoperatively and was appropriately extended depending on the severity of the case.

During the follow-up period, the patients were examined weekly; any complication was recorded and managed accordingly. The duration of the IMF extended for 2-3 weeks, after that the arch bars and/or wires were removed.

The outcome (dependent) variables included the treatment outcome, postoperative complications, and the duration of hospital stay. The predictor (independent) variables included the age of the patients (which was divided into two age groups 0-5 years and 6-12 years), gender, cause of trauma, the facial bones involved, the pattern of fracture (being with or without soft tissue injury), the presence of other injuries, the modality of treatment used (whether surgical treatment which consisted of closed reduction with indirect fixation or ORIF, or conservative treatment), and time between injury and treatment. Ethical approval of the local ethics committee was not required due to the retrospective observational nature of the study; the confidentiality of the patients was ensured.

Statistical analysis was performed using GraphPad Prism version 6 for Windows (GraphPad Software, La Jolla, CA, USA). For the descriptive analysis, percentages or the mean \pm standard deviations (SD) were recorded. All investigated variables were analyzed statistically using the Chi-square test or Fisher's exact test. The differences were considered significant at $p<0.05$.

\section{Results}

During the study period, 208 patients with maxillofacial fractures were admitted and treated, of those 63 patients (30.2\%) were children $\leq 12$ years with a mean age $( \pm S D)$ of $7( \pm 3.34)$ years (range $=1.5-12$ years), of these 57 were treated and were available for follow-up. The patients consisted of 40 male (70.2\%) and 17 female $(29.8 \%)$, making a male/female ratio of (2.3:1). Most patients belonged to the school-aged group $(n=35,61.4 \%)$, while the preschool-aged group consisted of 22 patients (38.6\%).

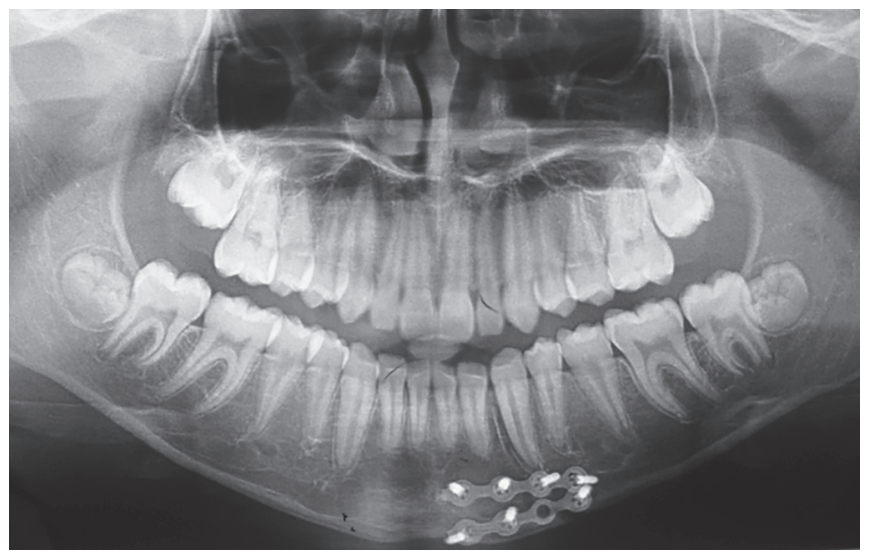

Fig. 2: A panoramic view of a 12-year-old patient with left parasymphyseal fracture of the mandible treated with 2 titanium miniplates 
The most common cause of injury was fall from height in 21 patients $(36.8 \%)$, followed by common fall injuries $(n=16$, $28.1 \%), \operatorname{RTA}(n=11,19.3 \%)$, hit by objects $(n=5,8.8 \%)$, and violence $(n=4,7 \%)$.

The pattern of injury encountered in 41 patients (72\%) was a combination of both soft tissue and skeletal injuries, while solitary skeletal injuries were seen in the remaining 16 patients (28\%). Twelve patients (21\%) sustained concurrent injuries involving other parts of the body. Limb fractures and lacerations were the most common injuries.

Eighty-three fractures were identified in 57 patients; 28 patients (49.2\%) had 41 isolated mandibular fractures, 16 patients (28\%) presented with 20 dentoalveolar fractures, 10 patients (17.5\%) presented with 12 fractures at the upper and midfacial region, and the remaining 3 patients (5.3\%) suffered from 10 fractures in multiple facial regions (Table 1).

Forty patients (70.2\%) were treated surgically and 17 patients (29.8\%) were managed conservatively. Surgical treatment consisted of closed reduction and immobilization for $2-3$ weeks in 31 patients (77.5\%). Open reduction and internal fixation with titanium miniplates was performed in four patients (10\%), and in five patients (12.5\%) with dentoalveolar fracture, the treatment consisted of dental extraction and suturing. Most of the patients ( $n=32,56.1 \%)$ were treated $<24$ hours of their injury, 17 patients (29.8\%) received their treatment within $24-72$ hours of injury, and in 8 patients (14\%) the treatment was $>72$ hours after injury.

Generally, during the follow-up period there were no major complications in any type of fracture. All fractures healed uneventfully. Evaluating neurological disturbance was rather difficult in children. Complications occurred in eight patients (14\%); these were deviation during mouth opening $(n=4,50 \%)$ and malunion ( $n=4,50 \%)$.

Table 2 summarizes the results of comparison of the investigated variables between the two age groups. The variables that were significantly different between the two groups were the cause of injury, the site of injury, and the type of treatment (Fig. 3).

The differences in the distribution of the anatomical sites of mandibular fractures and the upper and middle face fractures between the two age groups was statistically not significant ( $p$ value $=0.20$ and 0.63 , respectively).

Table 1: Anatomical sites of the facial fractures

\begin{tabular}{ll}
\hline Fracture site & Number of fractures (\%) \\
\hline Mandible & $\mathbf{4 5}(\mathbf{5 4 . 2 )}$ \\
Condyle & $20(44.4)$ \\
Para-symphyseal & $14(31.1)$ \\
Symphyseal & $7(15.6)$ \\
Angle & $3(6.7)$ \\
Ramus & $1(2.2)$ \\
Dentoalveolar & $\mathbf{2 5 ( 3 0 . 1 )}$ \\
Upper & $17(68)$ \\
Lower & $8(32)$ \\
Upper and midface & $\mathbf{1 3 ( 1 5 . 7 )}$ \\
Nasal & $6(46.2)$ \\
Maxilla & $4(30.8)$ \\
Frontal & $3(23)$ \\
Total & $\mathbf{8 3 ( 1 0 0 )}$ \\
\hline
\end{tabular}

Table 2: Comparison of the investigated variables between the two age groups

\begin{tabular}{|c|c|c|c|}
\hline Variable & $\begin{array}{l}\text { Preschool-age } \\
\text { group } \\
\text { (0-5 years) }\end{array}$ & $\begin{array}{l}\text { School-age } \\
\text { group } \\
\text { (6-12 years) }\end{array}$ & $p$ value \\
\hline \multicolumn{4}{|l|}{ Gender } \\
\hline Male & 14 & 26 & $0.553[\mathrm{NS}]^{*}$ \\
\hline Female & 8 & 9 & \\
\hline \multicolumn{4}{|l|}{ Cause of injury } \\
\hline Common falls & 3 & 13 & $0.018[S]^{\dagger}$ \\
\hline Hit by objects & 2 & 3 & \\
\hline Fall from height & 14 & 7 & \\
\hline RTA & 2 & 9 & \\
\hline Violence & 1 & 3 & \\
\hline \multicolumn{4}{|l|}{ Pattern of injury } \\
\hline Solitary skeletal & 7 & 13 & $0.79[\mathrm{NS}]^{*}$ \\
\hline $\begin{array}{l}\text { Combination soft } \\
\text { tissue and skeletal }\end{array}$ & 17 & 26 & \\
\hline \multicolumn{4}{|c|}{ Site of injury/number of fractures } \\
\hline Mandible & 20 & 25 & $0.009[\mathrm{~S}]^{\dagger}$ \\
\hline Dentoalveolar & 3 & 22 & \\
\hline $\begin{array}{l}\text { Upper and middle } \\
\text { face }\end{array}$ & 7 & 6 & \\
\hline \multicolumn{4}{|l|}{ Treatment } \\
\hline Conservative & 11 & 6 & $0.016[S]^{*}$ \\
\hline Surgical & 11 & 29 & \\
\hline \multicolumn{4}{|l|}{ Complication rate } \\
\hline Complications & 4 & 4 & $0.697[\mathrm{NS}]^{*}$ \\
\hline No complications & 18 & 31 & \\
\hline \multicolumn{4}{|c|}{ Time lapse between injury and treatment } \\
\hline$<24$ hours & 13 & 19 & $0.695[\mathrm{NS}]^{\dagger}$ \\
\hline 24-72 hours & 7 & 10 & \\
\hline$>72$ hours & 2 & 6 & \\
\hline
\end{tabular}

*Fisher's exact test

${ }^{\dagger}$ Chi-square

[S] significant

[NS] nonsignificant

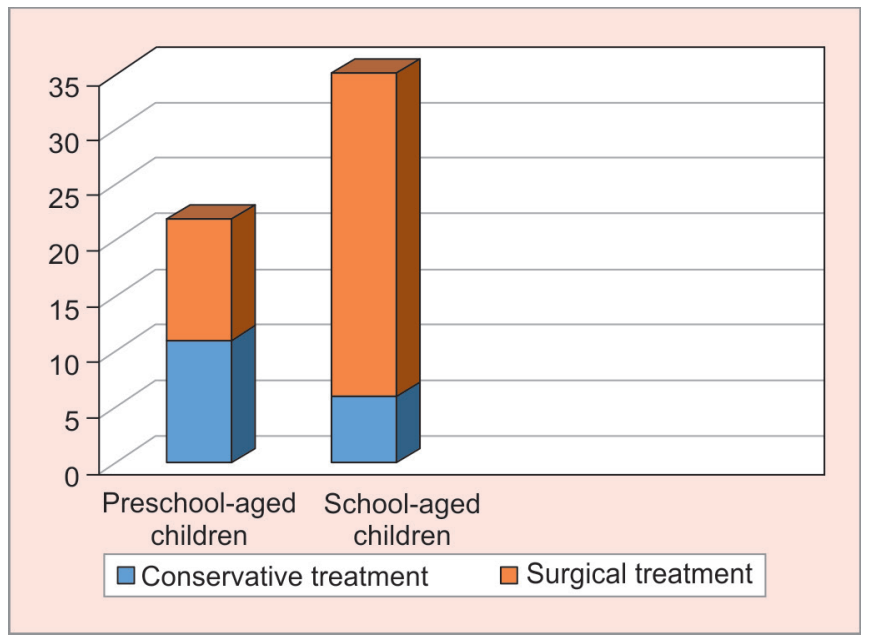

Fig. 3: Distribution of the type of treatment between the preschool-and school-aged children 


\section{Discussion}

The general characteristics of pediatric maxillofacial trauma vary from one country to another and even within the same country because of social, cultural, and environmental factors, and the incidence and etiology of pediatric maxillofacial injuries are also affected by age-related activities. ${ }^{8-10}$

The incidence of facial injuries in children up to 12 years in the present study was $30.2 \%$, which is higher than that reported by most studies in which the incidence of maxillofacial fractures range from $1 \%$ to $19 \%$ being about $1-12 \%$ in children below 5 years of age. ${ }^{2,6,8,10-17}$

In agreement with previous studies, ${ }^{8,10,18-20}$ it was found that the incidence of facial injuries before the age of 5 years was lower and it increased with the beginning of school. In the current study, most patients were in the school-age group, and this can be explained by the fact that school-aged children engage in more activities in addition to the anatomical changes that are associated with the facial growth that make them more susceptible to facial fractures. On the contrary, children during the first years of life usually live in a more protected environment under parental supervision and their major activity is within the family house. ${ }^{10,18}$

The present study confirmed that male children are approximately affected twice more than female children, which is attributed to higher level of physical activity among male children. Our findings are in line with other studies $s^{2,7,18}$ that reported a male/ female ratio of fractures ranging from 2.1:1 to 3.1:1. The male/ female ratio in this study increased with age; however, the gender difference between the two age groups was statistically not significant which is in keeping with other studies. ${ }^{9-11}$

Generally, falls constitute a common cause of injury in children; ${ }^{6,7,22}$ it was observed that many children enrolled in this study lived in suburban areas with low socio-economic status and parental neglect. Fall from height, in this study, was the most common cause of facial fractures in children younger than 5 years of age; a similar observation was made by Baffano et al. ${ }^{10}$ and children in this age group may be prone to falls due to the uncertainty of motion and lack of coordination in the first years of life that would prevent them from adequately shielding themselves.

Hit with hard objects and interpersonal violence-related fractures occurred in $8.8 \%$ and $7 \%$ of the patients, respectively, which is within the range reported by other studies. ${ }^{714,17,21-23}$ To note is that this study demonstrated some changes in the etiologies of facial injuries compared with a previous study conducted at the same institution during the period extending from 2010 to $20144^{6}$ these changes included an increased incidence of interpersonal violence and the absence of missile injuries. The fact that no missile injuries were recorded in this study may indicate a reduction in the terrorist actions and in the degree of the civilian unrest that afflicted this country after 2003.

The mandible was the most common fractured site, which is similar to the findings reported from different parts of the world; ${ }^{12,24,25}$ this vulnerability of mandible is probably due to the high tooth to bone ratio caused by the presence of permanent teeth buds and the unique curvature form. The present study revealed that the condyle was the most affected mandibular site, supporting earlier studies. ${ }^{11,19,25}$ Children have characteristically high incidence of condylar fractures which occur mostly in the neck of the condyle due to some anatomical factors that favor this site, such as the high vascularization of the condyle in children and a slender neck with poor resistance to impact forces during falls. ${ }^{18}$ Ferreira et al ${ }^{25}$ and
Imahara et al. ${ }^{12}$ reported that mandibular fractures occur more often in older age groups; the results of current study showed that the mandibular fractures were uniformly distributed between the two age groups without significant differences.

In the present study, dentoalveolar fractures constituted $30.1 \%$ of the total fractures, mostly involving the anterior region of the maxilla, which is more prone to injuries due to its forward position; a similar observation was made by Fariniuk et al. ${ }^{26}$ and Ashrafullaha et al. ${ }^{21}$

In the preschool-aged children, the incidence of midfacial fracture is less because of prominence of cranium and more elasticity of facial bone than the adults. ${ }^{21}$ Nasal bone fractures were the least frequently recorded injury; this is in line with other reports, ${ }^{6,16}$ yet in contrast with other studies. ${ }^{17,27}$

Treatment of pediatric facial fractures depends on the type and site of fractures and on the skeletal and dental development. ${ }^{8}$ Although there is still no consensus on the treatment of maxillofacial fractures in pediatric patients, ${ }^{10}$ the specific age-related status of the growing face and dentition development should be a major concern when choosing the type of treatment ${ }^{2,13,28}$ and closed treatment is preferred by many authors, ${ }^{29}$ although latrou et al. ${ }^{30}$ reported that open reduction and internal fixation of most fractures provides quick and satisfactory management of fractures in children. Younger patients have a faster healing rate than adults; therefore, treatment is usually performed without delay and can be limited to observation or closed reduction in minimally or nondisplaced fractures. ${ }^{2,28}$ Immobilization time should be shorter than in adults ( 2 vs $4-6$ weeks). ${ }^{15}$

Most of the patients in this study $(35 / 57,61.4 \%)$ were schoolaged children; $83 \%$ of them $(n=29)$ were treated surgically compared with $17 \%(n=6)$ who received conservative treatment; this increased likelihood of surgical treatment in older children is supported in the literature. ${ }^{2}$

The reported complication rate ranges from $1.1 \%$ to $6.8 \% .{ }^{6,17,31}$ In this study, complications were reported in eight patients (14\%) and they were confined to malunion and slight deviation during mouth opening with even distribution between the groups. Other complications related to growth disturbances could not be demonstrated in this study due to the short follow-up period; this limitation in follow-up of patients was also acknowledged by other authors. $^{18,32}$

This study is limited by its observational nature, small sample size and a short follow-up period, and the fact that it is a single institution study.

\section{Conclusion}

Pediatric facial fractures occur most frequently in school-aged children with male predominance, falls are the most common cause of facial fractures in children, the incidence of mandibular fractures is high with the condyle being the most affected site, conservative and surgical treatments were performed with significant difference between the two age groups, the surgical treatment was indicated in most of the older age group and no major complications were encountered in this study, and patients in growing phase should be monitored periodically to detect early facial asymmetry or malocclusion.

\section{Clinical Significance}

Facial fractures in children require special considerations in their management due to many characteristic features of the facial 
skeleton of the growing child and the possibility of growth disturbances that may result from these injuries, the incidence of facial fractures in children increases with the beginning of school, and their treatment in school-aged children tends to be surgical rather than conservative.

\section{References}

1. Ferreira P, Barbosa J, et al. Changes in the characteristics of facial fractures in children and adolescents in Portugal 1993-2012. Br J Oral Maxillofac Surg 2015;53(3):251-256. DOI: 10.1016/j.bjoms.2014.12.002.

2. Zimmermann CE, Troulis MJ, et al. Pediatric facial fractures: recent advances in prevention, diagnosis and management. Int J Oral Maxillofac Surg 2006;35(1):2-13. DOI: 10.1016/j.ijom.2005.09.014.

3. Andrade NN, Choradia S, et al. An institutional experience in the management of pediatric mandibular fractures: a study of 74 cases. J Craniomaxillofac Surg 2015;43(7):995-999. DOI: 10.1016/ j.jcms.2015.03.020.

4. Thorén $H$, lizuka $T$, et al. Different patterns of mandibular fractures in children. An analysis of 220 fractures in 157 patients. J Craniomaxillofac Surg 1992;20(7):292-296. DOI: 10.1016/S10105182(05)80398-1.

5. Mukherjee CG, Mukherjee U. Maxillofacial trauma in children. Int J Clin Pediatr Dent 2012;5(3):231-236. DOI: 10.5005/jp-journals-10005-1174.

6. Bede SY, Ismael WK, et al. Patterns of pediatric maxillofacial injuries. J Craniofac Surg 2016;27(3):e271-e275. DOI: 10.1097/ SCS.0000000000002502.

7. Hawramy FA. Maxillofacial trauma among children below 15 years in Sulaimania city//raq. Kufa Med J 2011;14:225-230.

8. Ogunlewe MO, James $\mathrm{O}$, et al. Pattern of paediatric maxillofacial fractures in Lagos, Nigeria. Int J Clin Pediatr Dent 2006;16(5):358-362. DOI: 10.1111/j.1365-263X.2006.00757.x.

9. Li Z, Li ZB. Characteristic changes of pediatric maxillofacial fractures in China during the past 20 years. J Oral Maxillofac Surg 2008;66(11):2239-2242. DOI: 10.1016/j.joms.2007.12.032.

10. Boffano P, Roccia F, et al. European Maxillofacial Trauma (EURMAT) in children: a multicenter and prospective study. Oral Surg Oral Med Oral Pathol Oral Radiol 2015;119(5):499-504. DOI: 10.1016/ j.oooo.2014.12.012.

11. Gassner R, Tuli T, et al. Cranio-maxillofacial trauma: a 10 year review of 9,543 cases with 21,067 injuries. J Craniomaxillofac Surg 2003;31(1):51-61. DOI: 10.1016/S1010-5182(02)00168-3.

12. Imahara SD, Hopper RA, et al. Patterns and outcomes of pediatric facial fractures in the United States: a survey of the National Trauma Data Bank. J Am Coll Surg 2008;207(5):710-716. DOI: 10.1016/ j.jamcollsurg.2008.06.333.

13. Hatef DA, Cole PD, et al. Contemporary management of pediatric facial trauma. Curr Opin Otolaryngol Head Neck Surg 2009;17(4): 308-314. DOI: 10.1097/MOO.0b013e32832d95a0.

14. Okoje VN, Alonge TO, et al. Changing pattern of pediatric maxillofacial injuries at the Accident and Emergency Department of the University Teaching Hospital, Ibadan - a four-year experience. Prehosp Disaster Med 2010;25(1):68-71. DOI: 10.1017/S1049023X0000769X.

15. Wheeler J, Phillips J. Pediatric facial fractures and potential longterm growth disturbances. Craniomaxillofac Trauma Reconstr 2011;4(1):43-52. DOI: 10.1055/s-0031-1272901.
16. Singh RBPJ, Chaitan SN, et al. Maxillofacial injuries in the pediatric patient: an overview. World J Dent 2011;2:77-81. DOI: 10.5005/ jp-journals-10015-1060.

17. Kim SH, Lee SH, et al. Analysis of $809 \mathrm{facial}$ bone fractures in a pediatric and adolescent population. Arch Plast Surg 2012;39(6):606-611. DOI: 10.5999/aps.2012.39.6.606.

18. Munante-Cardenas JL, Asprino L, et al. Mandibular fractures in a group of Brazilian subjects under 18 years of age: a epidemiological analysis. Int J Pediatr Otorhinolaryngol 2010;74(11):1276-1280. DOI: 10.1016/j.jporl.2010.08.004.

19. Rahman RA, Ramli R, et al. Maxillofacial trauma of pediatric patients in Malaysia: a retrospective study from 1999 to 2001 in three hospitals. Int J Pediatr Otorhinolaryngol 2007;71(6):929-936. DOI: 10.1016/ j.ijporl.2007.03.003.

20. Eggensperger Wymann NM, Holzle $A$, et al. Pediatric craniofacial trauma. J Oral Maxillofac Surg 2008;66(1):58-64. DOI: 10.1016/ j.joms.2007.04.023.

21. Ashrafullah, Pandey RK, et al. The incidence of facial injuries in children in Indian population: a retrospective study. J Oral Biol Craniofac Res 2018;8(2):82-85. DOI: 10.1016/j.jobcr.2017.09.006.

22. Kumaraswamy SV, Madan N, et al. Pediatric injuries in maxillofacial trauma: a 5 year study. J Maxillofac Oral Surg 2009;8(2):150-153. DOI: 10.1007/s12663-009-0037-4.

23. lida S, Matsuya T. Paediatric maxillofacial fractures: their aetiological characters and fracture patterns. J Craniomaxillofac Surg 2002;30(4):237-241. DOI: $10.1054 / \mathrm{jcms} .2002 .0295$.

24. Karim T, Khan AH, et al. Trauma of facial skeleton in children: an indian perspective. Indian J Surg 2010;72(3):232-235. DOI: 10.1007/s12262010-0056-x.

25. Ferreira PC, Amarante JM, et al. Retrospective study of 1251 maxillofacial fractures in children and adolescents. Plast Reconstr Surg 2005;115(6):1500-1508. DOI: 10.1097/01.PRS.0000160268.20294.FD.

26. Fariniuk LF, Souza MH, et al. Evaluation of care of dentoalveolar trauma. J Appl Oral Sci 2010;18(4):343-345. DOI: 10.1590/S167877572010000400004.

27. Nardis Ada C, Costa SA, et al. Patterns of paediatric facial fractures in a hospital of Sao Paulo, Brazil: a retrospective study of 3 years. J Craniomaxillofacial Surg 2013;41(3):226-229. DOI: 10.1016/ j.jcms.2012.09.005.

28. Alcala-Galiano A, Arribas-Garcia IJ, et al. Pediatric facial fractures: children are not just small adults. Radiographics 2008;28(2):441-461. DOI: 10.1148/rg.282075060.

29. Ghasemzadeh A, Mundinger GS, et al. Treatment of pediatric condylar fractures: a 20-year experience. Plast Reconstr Surg 2015;136(6): 1279-1288. DOI: 10.1097/PRS.0000000000001811.

30. Iatrou I, Theologie-Lygidakis $\mathrm{N}$, et al. Surgical protocols and outcome for the treatment of maxillofacial fractures in children: 9 years' experience. J Craniomaxillofac Surg 2010;38(7):511-516. DOI: 10.1016/j.jcms.2010.02.008.

31. Infante Cossio P, Espin Galvez F, et al. Mandibular fractures in children. A retrospective study of 99 fractures in 59 patients. Int J Oral Maxillofac Surg 1994;23(6 Pt 1):329-331.

32. Ferreira PC, Barbosa J, et al. Associated injuries in pediatric patients with facial fractures in Portugal: analysis of 1416 patients. J Craniomaxillofac Surg 2015;43(4):437-443. DOI: 10.1016/ j.jcms.2015.01.008. 